\title{
Immunogenetics: changing the face of immunodeficiency
}

\author{
Alison M Jones, Hubert B Gaspar
}

Primary immunodeficiency is increasingly recognised in both children and adults. Although clearly defined disorders are individually rare, collectively they form a significant group. The molecular basis of several disorders has been known for over a decade, but in the past 10 years there has been a massive increase in the definition of defects underlying many immunodeficiencies.

Management of immunodeficiency has historically consisted of supportive treatment, including antibiotics, immunoglobulin (Ig) replacement, and in some cases, immunomodulation and immunosuppression. Bone marrow transplantation has been standard treatment for the past 20 years, but only for clearly defined cases of severe combined immunodeficiency (SCID) and a few other disorders known to have a very poor outlook without bone marrow transplantation. Accumulating worldwide experience is now providing evidence for poor long term prognoses in many other situations, even with optimal medical treatment. Bone marrow transplantation is therefore being considered for increasing numbers of children affected by these disorders, and, in parallel with this, there is a pressing need to define individual disorders as accurately and as early as possible.

The recent increase in knowledge of the molecular defects underlying many immunodeficiencies has led to several improvements in diagnosis and management.

First, precise molecular diagnosis is now possible in many cases, allowing earlier decisions to be made about the most appropriate management. This is particularly applicable in children who have evidence of combined (cellular and humoral) immunodeficiency, but with "milder" clinical phenotypes than infants with classical SCID. Some of these children are found to have identical molecular defects to those causing SCID, and in these cases the long term outlook is now known to be poor enough to justify bone marrow transplantation at an early stage.

Second, accurate carrier detection and first trimester prenatal diagnosis are possible in any family where the precise mutation has been defined. In some cases prenatal diagnosis of an affected fetus may not lead to termination of pregnancy, but can allow preparation for bone marrow transplantation early in the neonatal period, or even in utero in selected cases. Earlier bone marrow transplantation is associated with a greater chance of a successful outcome.

Third, knowledge of the molecular basis of immunodeficiencies allows further research into the mechanisms of the immune defects, with the possibility of designing more rational treatment in some cases, and for developing strategies for somatic gene therapy.

\section{Specific disorders}

Those immunodeficiencies for which the underlying molecular defects have been defined are summarised in tables 1 and 2 . In several of these disorders, knowledge of the molecular basis has led to the improvements in management outlined above. In other cases ongoing research is continuing to add to our understanding of the molecular mechanisms of immune function. It is not within the scope of this review to go into detail for every disorder, so several illustrative diseases will be discussed.

\section{X linked agammaglobulinaemia (XLA)}

$\mathrm{X}$ linked agammaglobulinaemia is the archetypal humoral immunodeficiency, presenting in its classical form with susceptibility to bacterial infection, absent or low circulating mature B cells, and absence of all immunoglobulin isotypes. ${ }^{1}$ Standard treatment is with life long immunoglobulin replacement. The outlook is good provided that adequate IgG levels are maintained and infections are promptly treated. There is, however, a significant risk of enteroviral infection, and chronic meningoencephalitis can develop despite immunoglobulin replacement therapy. ${ }^{2}$ The diagnosis of XLA has been made on lack of peripheral B lymphocytes, absence of immunoglobulin production, and in some cases an X linked pedigree. However, girls with congenital agammaglobulinaemia and absent $\mathrm{B}$ cells ${ }^{3}$ and boys with a similar immunological profile but from an autosomal pedigree have also been reported, suggesting that the same immunophenotype can arise from a number of molecular defects.

In 1993, two groups identified the gene defective in XLA, one using a positional cloning strategy and another using a reverse genetic approach. ${ }^{45}$ Subsequently designated Btk (Bruton's tyrosine kinase), the gene is a non-receptor tyrosine kinase expressed in the $\mathrm{B}$ and myelomonocytic cell lineages but not in $\mathrm{T}$ cells. Btk is activated following stimulation of several cell surface receptors including most importantly the B cell receptor. ${ }^{6}$ In addition, interaction of Btk with a variety of intracellular signalling molecules including $\mathrm{PIP}_{3}$ (phosphatidylinositol-3,4,5-trisphosphate) and PLC $\gamma 1$ (phospholipase $\mathrm{C} \gamma 1$ ) is crucial for regulation of the sustained calcium signal in response to BCR engagement (reviewed in ${ }^{7}$ ). However, despite the large volume of experimental data, it is still unclear precisely how defects in Btk lead to the arrest in B cell maturation seen in XLA. 
The identification of the Btk gene defect allows unambiguous assignment of a molecular diagnosis to individuals with XLA and to female carriers. This is particularly important as defects in $\mu$ heavy chain and $\lambda 5 / 14.1$ surrogate light chain (components of the pre-B cell receptor) have also been shown to give rise to congenital agammaglobulinaemia. ${ }^{89}$ Furthermore, screening of individuals with atypical or less severe XLA phenotypes, including those previously labelled as common variable immunodeficiency or immunoglobulin subclass deficiency, has shown that some of these individuals may also have Btk defects. ${ }^{10}$

Mutation detection in XLA has traditionally been carried out by initial screening of the 19 exons of the Btk gene by single stranded conformation polymorphism (SSCP) analysis and subsequent direct sequencing of the affected exon. This is a time consuming technique that may take months to complete, and has a sensitivity of only $90 \%$. More recently generation of specific anti-Btk antibodies has allowed development of more rapid methods of diagnosis. Analysis of Btk protein expression in peripheral blood mononuclear cells of XLA patients by intracellular fluorescence activated cell sorter (FACS) or western blot analysis shows that over $90 \%$ lack Btk expression. ${ }^{11}{ }^{12}$ These techniques have also been useful in determining carrier status. In obligate carriers of XLA, intracellular FACS staining of monocytes shows a dual population of Btk expressing and Btk non-expressing cells since monocytes are randomly $\mathrm{X}$ inactivated in these women. ${ }^{11}$ Similarly, if an XLA patient expresses a Btk protein of abnormal size, western blot analysis of monocytes from carrier females shows expression of an abnormal and normal sized band, thereby confirming carrier status.

\section{CD40 ligand deficiency}

$\mathrm{X}$ linked hyper IgM syndrome (XHM) has been recognised since $1966,{ }^{13}$ its characteristic immunological phenotype including very low IgG and IgA levels, normal or raised IgM, nor- mal lymphocyte subpopulations, and apparently normal $\mathrm{T}$ cell function. The clinical phenotype is one of susceptibility to bacterial infection, but for many years before the responsible gene was identified it was known that boys affected by XHM were susceptible to opportunistic infection with organisms such as Pneumocystis carinii. ${ }^{14}$ More recently, particular susceptibility to Cryptosporidium parvum has also been recognised. It was therefore not surprising when the gene responsible for XHM was identified in 1993 as that coding for CD40 ligand (CD40L), a surface molecule present on activated $\mathrm{T}$ cells. ${ }^{15-17} \mathrm{CD} 40 \mathrm{~L}$ is essential for immunoglobulin isotype switching through its interaction with CD40 on the surface of B cells, but it also plays an as yet undefined role in $\mathrm{T}$ cell function. $\mathrm{T}$ cell proliferative responses to a range of antigens have been shown to be defective in CD40L deficiency. ${ }^{18} \mathrm{CD} 40 \mathrm{~L}$ is also expressed on the surface of biliary epithelial cells, and CD40/CD40L interaction here is thought to be involved in control of intracellular pathogens such as $C$ parvum.

A further problem in CD40L deficiency is that of susceptibility to liver disease and liver/gastrointestinal malignancy, with a possible link between chronic cryptosporidial infection and sclerosing cholangitis. ${ }^{19}$ The European Society for Immunodeficiency database for CD40L deficiency currently contains clinical and molecular data from 113 affected males. The actuarial survival at 25 years is only $25 \%$, and the incidence of liver disease by the age of 20 years is $80 \% .{ }^{20}$ There is so far little apparent genotype/phenotype correlation, and there is considerable intrafamilial variation in clinical phenotype, so predictions of severity or likelihood of liver disease are not possible.

Knowledge of the molecular basis of XHM allows accurate diagnosis not only in boys who have a typical phenotype or a positive family history but also in some cases of previously undefined hypogammaglobulinaemia. Several adult males diagnosed as affected by common variable immunodeficiency (CVID) have recently been found to have CD40L deficiency.

Table 1 X linked immunodeficiencies

\begin{tabular}{|c|c|c|c|c|}
\hline $\begin{array}{l}\text { Disorder (year of definition of molecular } \\
\text { basis) }\end{array}$ & $\begin{array}{l}\text { Chromosomal } \\
\text { location }\end{array}$ & Gene & Function/defect & Diagnostic tests \\
\hline $\begin{array}{l}\text { X linked chronic granulomatous } \\
\text { disease (1986) }\end{array}$ & $\mathrm{Xp} 21$ & gp91phox & $\begin{array}{l}\text { Component of phagocytic NADPH } \\
\text { oxidase-phagocytic respiratory burst }\end{array}$ & $\begin{array}{l}\text { Nitroblue tetrazolium test } \\
\text { gp91phox by immunoblotting } \\
\text { Mutation analysis }\end{array}$ \\
\hline X linked agammaglobulinaemia (1993) & $\mathrm{Xq} 22$ & $\begin{array}{l}\text { Bruton's tyrosine } \\
\text { kinase (Btk) }\end{array}$ & $\begin{array}{l}\text { Intracellular signalling pathways } \\
\text { essential for pre-B cell maturation }\end{array}$ & $\begin{array}{l}\text { Btk by immunoblotting or FACS analysis } \\
\text { Mutation analysis }\end{array}$ \\
\hline $\begin{array}{l}\text { X linked severe combined } \\
\text { immunodeficiency (1993) }\end{array}$ & $\mathrm{Xq} 13$ & Common $\gamma$ chain $(\gamma c)$ & $\begin{array}{l}\text { Component of IL-2, 4, 7, 9, } 15 \text { cytokine } \\
\text { receptors; T and NK cell } \\
\text { development, T and B cell function }\end{array}$ & $\begin{array}{l}\text { CD154 expression on activated T cells by } \\
\text { FACS analysis } \\
\text { Mutation analysis }\end{array}$ \\
\hline $\begin{array}{l}\text { X linked hyper-IgM syndrome } \\
\text { (CD40 ligand deficiency) (1993) }\end{array}$ & $\mathrm{Xq} 26$ & CD40 ligand (CD154) & Isotype switching, $\mathrm{T}$ cell function & $\begin{array}{l}\text { CD145 expression on activated } \mathrm{T} \text { cells by } \\
\text { FACS analysis } \\
\text { Mutation analysis }\end{array}$ \\
\hline Wiskott-Aldrich syndrome (1994) & $\mathrm{Xp} 11$ & WASP & $\begin{array}{l}\text { Cytoskeletal architecture formation; } \\
\text { immune cell motility and trafficking }\end{array}$ & $\begin{array}{l}\text { WASP expression by immunoblotting } \\
\text { Mutation analysis }\end{array}$ \\
\hline $\begin{array}{l}\text { X linked lymphoproliferative } \\
\text { (Duncan's) syndrome (1998) }\end{array}$ & $\mathrm{Xq} 25$ & SAP & $\begin{array}{l}\text { Regulation of T cell responses to EBV } \\
\text { and ? other viral infections }\end{array}$ & $\begin{array}{l}\text { Mutation analysis } \\
\text { ?SAP expression-under development }\end{array}$ \\
\hline Properdin deficiency (1992) & $\mathrm{Xp} 21$ & Properdin & Terminal complement component & Properdin levels \\
\hline
\end{tabular}


Although these individuals may not develop the life threatening complications of CD40 ligand deficiency, other affected family members could have a more severe phenotype. Carrier detection and prenatal or early diagnosis is therefore important for relatives at risk. Any affected male who has a matched family donor is now recommended for bone marrow transplantation, and, where possible, unrelated donor bone marrow transplantation is offered to affected boys who have any evidence of liver disease or other complications.

\section{Wiskott-Aldrich syndrome}

Wiskott-Aldrich syndrome (WAS) is a rare $\mathrm{X}$ linked recessive disease characterised by immune dysregulation and microthrombocytopenia. ${ }^{21}$ Clinical manifestations of the immune dis- order include susceptibility to pyogenic, viral, and opportunistic infection, and eczema. There is usually progressive loss of $\mathrm{T}$ lymphocytes during childhood, with defects in proliferative and delayed type hypersensitivity responses, and deficient production of antibodies to both polysaccharide and protein antigens. Conventional supportive treatment for WAS includes prophylactic antibiotics and immunoglobulin, splenectomy for thrombocytopenia, and platelet transfusion in circumstances of life threatening haemorrhage. $^{22} 23$ Currently only allogeneic bone marrow transplantation can offer curative treatment for WAS. ${ }^{24}$ Like many other primary immunodeficiencies, there is considerable heterogeneity in the severity of clinical manifestations. In mildly affected individuals, diagnosis based on clinical criteria has proved difficult.

Table 2 Autosomal recessive immunodeficiencies

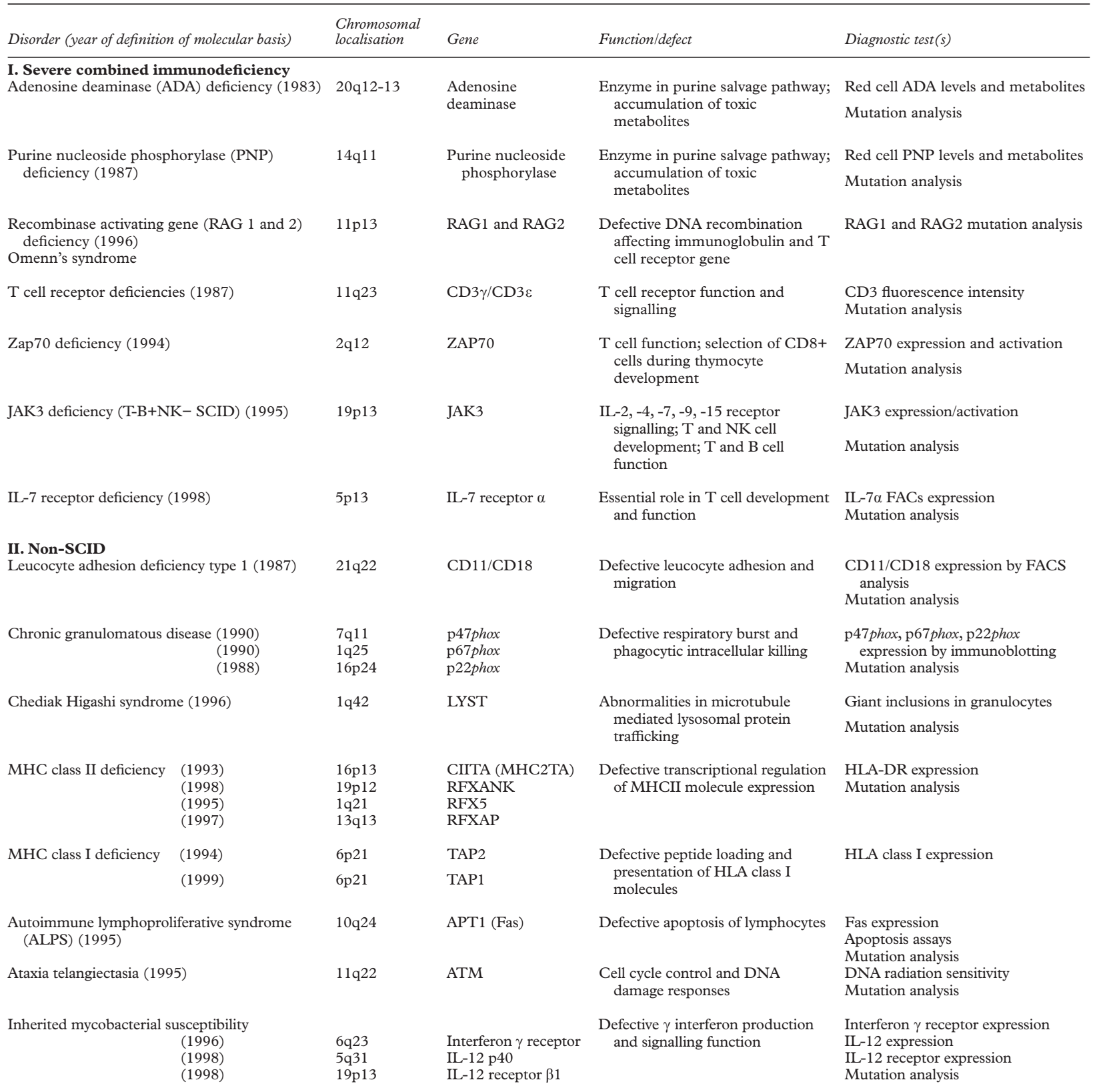

FACS, fluorescence activated cell sorting analysis; IL, interleukin; MHC, major histocompatibility complex; NK, natural killer cell; SCID, severe combined immune deficiency. 
However, the identification of WASP (WiskottAldrich syndrome protein), the gene defective in WAS, now allows definitive molecular diagnosis. To illustrate this, the clinical syndrome of microthrombocytopenia in X linked pedigrees (X linked thrombocytopenia or XLT) was originally thought to be a distinct genetic entity, but it has now also been shown to arise from WASP defects. ${ }^{25}$ Furthermore, in parallel with the development of protein based assays for XLA, similar tests are now available for the rapid detection of WASP abnormalities using immunoblotting and FACS analysis. ${ }^{26}{ }^{27}$

From a more basic perspective, the identification of the gene defect has allowed a greater understanding of the molecular pathogenesis of the WAS phenotype. The WASP gene encodes a 502 amino acid intracellular protein expressed exclusively in haematopoietic cells, ${ }^{28}$ which belongs to a recently defined family of more widely expressed proteins involved in transduction of signals from receptors on the cell surface to the actin cytoskeleton. The WASP family proteins are organised into modular domains defined by sequence homology and binding interactions with other signalling molecules (reviewed in ${ }^{29}$ ). Experimental data suggest that there are intrinsic defects in cytoskeletal architecture organisation and WAS immune cell motility and trafficking that may explain the variety of immunological abnormalities. Recent studies have shown WASP to cluster physically with polymerised actin and to act as a direct effector molecule for the small GTPase protein Cdc 42, which is critical for regulation of cytoskeletal structures. ${ }^{30}{ }^{31}$ Studies directly visualising WAS cells have shown that both WAS dendritic cells and macrophages have major abnormalities in the distribution of peripheral filamentous actin and fail to develop polarised filopodial extensions in response to chemotactic attractants. ${ }^{32} \mathrm{~T}$ cells from WAS patients show abnormalities of antigen receptor (CD3) stimulated proliferation (but not allostimulation), and both $\mathrm{T}$ and $\mathrm{B}$ lymphocytes have similar defects in the distribution of filamentous actin to those seen in dendritic cells and macrophages. ${ }^{34} 35$ These data suggest that a major component of the WAS immunophenotype may be abnormal initiation and regulation of immune responses owing to defective immune cell trafficking and motility.

\section{$\mathbf{X}$ linked lymphoproliferative disease (Duncan's syndrome)}

$\mathrm{X}$ linked lymphoproliferative disease (XLP) is a rare disorder characterised by a dysregulated immune response to Epstein-Barr virus (EBV). First recognised over 25 years ago, ${ }^{36}$ more than 80 kindreds have now been identified worldwide. The most usual presentation is with fulminant, often fatal acute EBV infection, but its phenotypic expression is highly variable. Other presentations include acquired hypogammaglobulinaemia, B cell lymphoma, aplastic anaemia, vasculitis, and lymphomatoid granulomatosis. ${ }^{38}$ In addition, this same study reports that 27 of 272 individuals $(10 \%)$ manifested an XLP phenotype without serological and in some cases genomic evidence of EBV infection. This, together with the variability in the clinical phenotype and the lack of a reliable diagnostic test, has made firm diagnosis of XLP extremely difficult. Historically, the diagnosis was based on a typical history with a suggestive pedigree, and sometimes the finding of raised anti-EBV antibody levels in obligate female carriers. In families where XLP has been considered likely, boys have been treated with long term immunoglobulin replacement in an attempt to protect them against EBV infection. However, this was not effective in at least one boy, who developed a haemophagocytic lymphohistiocytosis-like syndrome while receiving adequate doses of immunoglobulin.

The gene responsible for XLP was localised to Xq25 in 1990 by demonstration of an Xq25 deletion in an affected family, ${ }^{39}$ but it was not until 1998 that the gene was finally identified as that coding for SAP (signalling lymphocyte activating molecule associated protein). ${ }^{40} 41$ Signalling lymphocyte activating molecule (SLAM) is a B and T cell surface marker which forms a receptor-ligand pair, triggering of which coactivates $\mathrm{B}$ and $\mathrm{T}$ lymphocyte responses. SAP is a $15 \mathrm{kDa}$ protein that is primarily expressed in T cells and acts as a negative regulator of SLAM interactions. Mutations of SAP in XLP patients are postulated to dysregulate interactions between SLAM molecules on the surfaces of $T$ and $B$ cells, and result in uncontrolled $\mathrm{B}$ cell proliferation. Mutations in the SAP gene have so far been demonstrated in 13 males affected by XLP. However, there are still several families thought to carry XLP in whom no SAP mutations have been found, and the possibility remains that a second gene is involved.

Identification of the gene responsible for XLP allows accurate diagnosis by mutation detection, so that boys found to be affected can be recommended for bone marrow transplantation before the onset of progressive EBV disease or other complications. As the gene consists of only four exons, SSCP analysis (fig 1) or direct sequencing of genomic or cDNA should be relatively straightforward. It is also likely that use of an SAP antibody will the allow the development of a rapid protein based diagnostic assay. Unfortunately, lack of an identifiable mutation cannot at present exclude a diagnosis of XLP because of the uncertainty concerning a possible second genetic locus.

\section{Defects in the common $\gamma$ chain and JAK3 proteins}

Of the different molecular defects that result in SCID (tables 1 and 2), the most common is X linked severe combined immunodeficiency (X-SCID) which arises from defects in the common $\gamma$ chain $(\gamma \mathrm{c}) .{ }^{42}$ The characteristic immunophenotype in X-SCID consists of absence of $\mathrm{T}$ and NK (natural killer) cell development, but normal B cell numbers, although these are dysfunctional (T-B+NKSCID). A similar, though much rarer, clinical and immunological phenotype arises from an autosomal defect in the gene encoding the tyrosine kinase JAK3 (Janus associated 


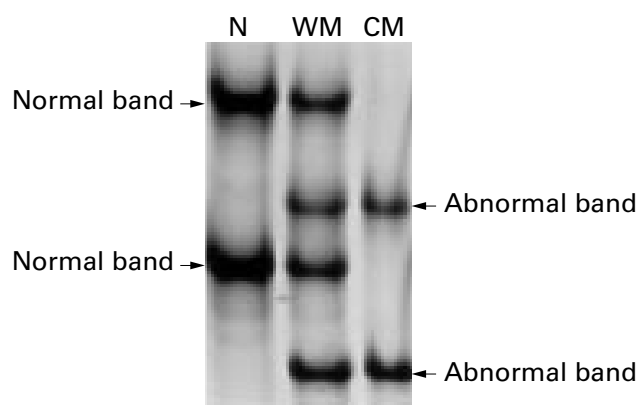

Figure 1 Single stranded conformational polymorphism (SSCP) analysis of the SAP gene in a family with XLP shows that the affected boy (CM) has a band shift in exon 2 in comparison with a normal control (N). Subsequent sequencing of exon 2 in $C M$ identified a $C$ to $G$ change at codon 54 which resulted in a tyrosine being replaced by a stop codon (Y54X) thus confirming the diagnosis of XLP. The boy's mother (WM) shows presence of both normal and abnormal bands by SSCP and is a carrier of the Y54X mutation.

kinase-3). ${ }^{43}{ }^{44}$ Details of the $\gamma \mathrm{c} / \mathrm{JAK} 3$ signalling pathway are illustrated in fig 2. Data from in vitro studies and from "knockout" mice models have shown that functional interleukin (IL)-7/ IL-7R and IL-15/IL-15R mediated signalling pathways are essential for normal $\mathrm{T}$ and $\mathrm{NK}$ cell development, respectively, thus explaining the lineage specific development defects present in X-SCID and JAK3 deficient patients. Abnormalities in IL- 2 and IL-4 signalling may further explain the functional B cell defects.

Identification of $\gamma c$ and JAK3 has had profound effects on the diagnosis and management of these conditions. Approximately two thirds of children with X-SCID have abnormal expression of $\gamma c$ on the surface of mononuclear cells, ${ }^{45}$ allowing confirmation of the molecular diagnosis by FACs analysis of peripheral blood mononuclear cells. In infants affected by $\mathrm{T}-\mathrm{B}+\mathrm{NK}-\mathrm{SCID}$ who have normal $\gamma \mathrm{c}$ expression, further dissection of the signalling pathway can now be undertaken. IL-2 stimulation of mononuclear cells results in tyrosine phos-

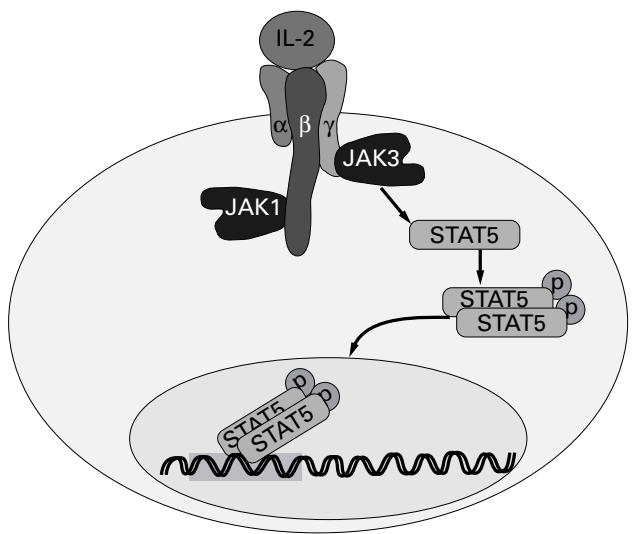

Figure $2 \gamma c$ is an essential component of the high affinity cytokine receptors for interleukin (IL) $-2,-4,-7,-9$ and -15 . Upon activation of these receptor complexes by cytokine, the $\mathcal{F A K} 3$ molecule, which binds selectively to $\gamma \mathrm{c}$, is itself activated and subsequently phosphorylates STAT5 (Signal Transducer and Activators of Transcription).

Phosphorylated STAT5 dimerises and then translocates to the nucleus where it binds to specific sites to initiate transcriptional events. phorylation of JAK3 at specific tyrosine based motifs. A monoclonal antibody directed against phosphotyrosine residues can be used to demonstrate JAK3 activation, so abnormalities in this signalling pathway can be detected at a protein level before genetic analysis. The variability in clinical presentation in these forms of SCID and especially in JAK3 deficiency again underlines the need to identify the molecular defect so that earlier referral for bone marrow transplantation can be made.

The ability to make a molecular diagnosis in utero in known carriers has also changed the treatment options for these types of SCID. Tissue typing can be carried out on DNA obtained from a CVS sample and used to identify potential donors. If a genotypically identical HLA match is available, transplantation can be undertaken almost immediately after birth before the onset of any infectious complications. If no related or unrelated donors are available, parental haplo-identical transplantation in utero may be an option. This has been attempted in a small number of SCID patients worldwide, with promising results. ${ }^{46}{ }^{47}$ Finally, establishment of the molecular defect opens up the possibility for treatment by somatic gene therapy. SCID caused by ADA deficiency was the first human disease to be treated in this way, although the results of initial trials were disappointing. ${ }^{48-51}$ Advances in vector technology and stem cell transduction have now led to another wave of clinical gene therapy trials, and the first study of gene therapy for X-SCID is currently under way in Europe. Furthermore, correction of the immunological abnormalities by gene transfer in a JAK3 deficient mouse model $^{52}$ suggests that gene therapy for JAK3 deficiency may also be possible.

\section{Summary}

Tables 1 and 2 highlight the enormous advances that have been made in the definition of the molecular defects underlying primary immunodeficiencies in the past decade. The identification of SAP as the gene defective in XLP now completes the molecular bases of all the recognised $\mathrm{X}$ linked syndromes. Of the autosomally inherited syndromes, only the genes for DiGeorge syndrome, hyper-IgE, and perhaps most importantly, common variable immunodeficiency remain to be elucidated.

The major clinical benefits of this information have primarily been in offering more accurate and rapid molecular diagnoses. The ability to make a molecular diagnosis also increases the options for earlier definitive treatments such as bone marrow transplantation and somatic gene therapy. Finally, as illustrated by the studies on the functions of WASP and the $\gamma \mathrm{c} / \mathrm{JAK}-3$ pathway, identification of the gene defect is the first step to understanding the molecular pathogenesis of the immunological abnormalities.

1 Bruton OC. Agammaglobulinaemia. Pediatrics 1952;9:722-7.

2 Hermaszewski RA, Webster AD. Primary hypogammaglobulinaemia: a survey of clinical manifestations and globulinaemia: a survey of clinical man

3 Conley ME, Sweinberg SK. Females with a disorder phenotypically identical to X linked agammaglobulinemia. $\mathcal{F}$ Clin Immunol 1992;12:139-43. 
4 Tsukada S, Saffran DC, Rawlings DJ, et al. Deficient expression of a B cell cytoplasmic tyrosine kinase in hu

5 Vetrie D, Vorechovsky I, Sideras P, et al. The gene involved in $\mathrm{X}$ linked agammaglobulinaemia is a member of the src family of protein-tyrosine kinases. Nature 1993;361:22633.

6 Kurosaki T. Molecular mechanisms in B cell antigen receptor signalling. Curr Opin Immunol 1997;9:309-18.

7 Rawlings DJ. Bruton's tyrosine kinase controls a sustained calcium signal essential for B lineage development and function. Clin Immunol 1999;91:243-53.

8 Yel L, Minegishi Y, Coustan SE, et al. Mutations in the mu heavy-chain gene in patients with agammaglobulinemia. $N$ Engl f Med 1996;335:1486-93.

9 Minegishi Y, Coustan SE, Wang YH, et al. Mutations in the human $\lambda 5 / 14.1$ gene result in $B$ cell deficiency and hummaglobulinemia. f Exp Med 1998;187:71-7.

10 Hashimoto S, Tsukada S, Matsushita M, et al. Identification of Bruton's tyrosine kinase (Btk) gene mutations and characterization of the derived proteins in $35 \mathrm{X}$ linked acterization of the derived proteins in 35 X linked agammaglobulinemia families: a nationwide
deficiency in Japan. Blood 1996;88:561- 73 .

11 Futatani T, Miyawaki T, Tsukada S, et al. Deficient expression of Bruton's tyrosine kinase in monocytes from X linked agammaglobulinemia as evaluated by a flow cytometric analysis and its clinical application to carrier detection. Blood 1998;15:595-602.

12 Gaspar HB, Lester T, Levinsky RJ, et al. Bruton's tyrosine kinase expression and activity in X linked agammaglobulinaemia (XLA): the use of protein analysis as a diagnostic indicator of XLA. Clin Exp Immunol 1998;111:334-8.

13 Rosen FS, Janeway CA. The gamma globulins: III. The antibody deficiency syndromes. $N$ Engl f Med 1966;275: 709-15.

14 Banatvala N, Davies J, Kanariou M, et al. Hypogammaglobulinaemia associated with normal or increased IgM (the hyper-IgM syndrome): a case series review. Arch Dis Child hyper-IgM synd

15 Aruffo A, Farrington M, Hollenbaugh D, et al. The CD40 Ligand, gp39, is defective in activated T cells from patients
with X-linked hyper-IgM syndrome. Cell 1993;72:291with

16 Di Santo JP, Bonnefoy JY, Gauchat JF, et al. CD40 ligand mutations in $\mathrm{X}$ linked immunodeficiency with hyper-IgM Nature 1993;361:541-3.

17 Korthauer U, Graf D, Mages $\mathrm{H}$, et al. Defective expression of T cell CD40 ligand causes X linked immunodeficiency with hyper-IgM. Nature 1993;361:539-41.

18 Ameratunga R, Lederman HM, Sullivan KE, et al. Defective antigen-induced lymphocyte proliferation in the $\mathrm{X}$ linked hyper-IgM syndrome. F Pediatr 1996;131:147-50.

19 Hayward AR, Levy J, Facchetti F, et al. Cholangiopathy and tumors of the pancreas, liver, and biliary tree in boys with $\mathrm{X}$-linked immunodeficiency with hyper-IgM. F Immunol 1997;158:977-83.

20 Levy J, Espanol-Boren T, Thomas C, et al. Clinical spectrum of X linked hyper-IgM syndrome. 7 Pediatr 1997 131:47-54.

21 Remold-O'Donnell E, Rosen FS, Kenney DM. Defects in Wiskott-Aldrich syndrome blood cells. Blood 1996;87: 2621-31.

22 Mullen CA, Anderson KD, Blaese RM. Splenectomy and/or bone marrow transplantation in the management of the Wiskott-Aldrich syndrome: long-term follow-up of 62 cases. Blood 1993;82:2961-6.

23 Litzman J, Jones A, Hann I, et al. Intravenous immunoglobulin, splenectomy, and antibiotic prophylaxis in Wiskott-Aldrich syndrome. Arch Dis Child 1996;75:436-9.

24 Ozsahin H, Le Deist F, Benkerrou M, et al. Bone marrow transplantation in 26 patients with Wiskott-Aldrich syndrome from a single center. $\mathcal{F}$ Pediatr 1996;129:238-44.

25 Villa A, Notarangelo L, Macchi P, et al. X linked thrombocytopenia and Wiskott-Aldrich syndrome are allelic diseases with mutations in the WASP gene. Nature Genet 1995;9:414-17.

26 MacCarthy Morrogh L, Gaspar HB, Wang Y-C, et al. Absence of expression of the Wiskott-Aldrich syndrome protein in peripheral blood cells of Wiskott-Aldrich protein in peripheral blood cells of Wiskott-Aldrich syndrom

27 Yamada M, Ohtsu M, Kobayashi I, et al. Flow cytometric analysis of Wiskott-Aldrich syndrome (WAS) protein in lymphocytes from WAS patients and their familial carriers. Blood 1999;93:756-7.

28 Derry JM, Ochs HD, Francke U. Isolation of a novel gene mutated in Wiskott-Aldrich syndrome. Cell 1994;78:63544.
29 Ramesh N, Anton IM, Martinez-Quiles N, et al. Waltzing with WASP. Trends Cell Biol 1999;9:15-19.

30 Aspenstrom P, Lindberg U, Hall A. Two GTPases, Cdc42 and Rac, bind directly to a protein implicated in the mmunodeficiency disorder Wiskott-Aldrich syndrome. Curr Biol 1996;6:70-5.

31 Symons M, Derry JM, Karlak B, et al. Wiskott-Aldrich syndrome protein, a novel effector for the GTPase CDC42Hs, is implicated in actin polymerization. Cell 1996;84:723-34.

32 Binks M, Jones GE, Brickell PM, et al. Intrinsic dendritic cell abnormalities in Wiskott-Aldrich syndrome. Eur 7 Immunol 1998;28:3259-67.

33 Zicha D, Allen WE, Brickell PM, et al. Chemotaxis of macrophages is abolished in the Wiskott-Aldrich syndrome. $\mathrm{Br}$ 7 Haematol 1998;101:659-65.

34 Gallego MD, Santamaria M, Pena J, et al. Defective actin reorganization and polymerization of Wiskott-Aldrich $\mathrm{T}$ cells in response to CD3-mediated stimulation. Blood 1997;90:3089-97.

35 Candotti F, Facchetti F, Blanzuoli L, et al. Retrovirusmediated WASP gene transfer corrects defective actin polymerization in B cell lines from Wiskott-Aldrich syndrome patients carrying "null" mutations. Gene Ther 1999;6:1170-4.

36 Bar RS, DeLor CJ, Clausen KP, et al. Fatal infectious mononucleosis in a family. N Engl f Med 1974;290:363-7.

37 Purtilo DT, Cassel CK, Yang JPS, et al. X linked recessive progressive combined variable immunodeficiency (Duncan's disease). Lancet 1975;i:935-41.

38 Seemayer TA, Gross TG, Egeler RM, et al. X linked lymphoproliferative disease: twenty-five years after the discovery. Pediatr Res 1995;38:471-8.

39 Sanger WG, Grierson HL, Skare J, et al. Partial Xq25 deletion in a family with $\mathrm{x}$-linked lympho proliferative disease. Cancer Genet Cytogenet 1990;47:163-9.

40 Coffey AJ, Brooksbank RA, Brandau O, et al. Host response to $\mathrm{EBV}$ infection in $\mathrm{X}$ linked lymphoproliferative disease results from mutations in an $\mathrm{SH} 2$-domain encoding gene. Nature Genet 1998;20:129-35.

41 Sayos J, Wu C, Morra M, et al. The X linked lymphoproliferative-disease gene product SAP regulates signals induced through the co-receptor SLAM. Nature 1998;395:462-9.

42 Noguchi M, Yi H, Rosenblatt HM, et al. Interleukin-2 receptor $\gamma$ chain mutation results in $\mathrm{X}$ linked severe combined immunodeficiency in humans. Cell 1993;73: 147-57

43 Macchi P, Villa A, Gillani S, et al. Mutations of Jak-3 gene in patients with autosomal severe combined immune deficiency (SCID). Nature 1995;377:65-8.

44 Russell SM, Tayebi N, Nakajima H, et al. Mutation of Jak3 in a patient with SCID: essential role of Jak3 in lymphoid development. Science 1995;270:797-800.

45 Puck JM, Pepper AE, Henthorn PS, et al. Mutation analysis of IL2RG in human X linked severe combined immunodeficiency. Blood 1997;89:1968-77.

46 Flake AW, Roncarolo MG, Puck JM, et al. Treatment of X linked severe combined immunodeficiency by in utero transplantation of paternal bone marrow. $N$ Engl f Med 996;335:1806-10.

47 Wengler GS, Lanfranchi A, Frusca $\mathrm{T}$, et al. In-utero transplantation of parental CD34 haematopoietic progenitor cells in a patient with $\mathrm{X}$ linked severe combined immunodeficiency (SCIDXI). Lancet 1996;348:1484-7.

48 Blaese RM, Culver KW, Miller AD, et al. T lymphocytedirected gene therapy for ADA-SCID: initial trial results after 4 years. Science 1995;270:475-80.

49 Bordignon C, Notarangelo LD, Nobili N, et al. Gene therapy in peripheral blood lymphocytes and bone marrow for ADA-immunodeficient patients. Science 1995;270:4705.

50 Hoogerbrugge PM, van Beusechem VW, Fischer A, et al. Bone marrow gene transfer in three patients with adenosine deaminase deficiency. Gene Ther 1996;3:179-83.

51 Kohn DB, Hershfield MS, Carbonaro D, et al. T lymphocytes with a normal ADA gene accumulate after transplantation of transduced autologous umbilical cord transplantation of transduced autologous umbilical cord Nature Med 1998;4:775-80.

52 Bunting KD, Sangster MY, Ihle JN, et al. Restoration of lymphocyte function in Janus kinase 3-deficient mice by retroviral-mediated gene transfer. Nature Med 1998;4:58- 